\title{
Positionality and Possibility: Reframing Tactics and Strategies for Graduate Student Community Engagement
}

\author{
Adam Hubrig \\ University of Nebraska-Lincoln \\ Marcus Meade \\ University of Virginia
}

\author{
Katie McWain \\ University of Nebraska-Lincoln \\ Rachael W. Shah \\ University of Nebraska-Lincoln
}

\begin{abstract}
Drawing on the authors' experiences initiating and directing a community partnership program, this article illustrates how graduate students who lead engagement programs can be caught between forces that pull them toward tactical partnerships unaffiliated with the university and strategic partnerships incorporated into university departments. Conceived as distinct models by philosopher de Certeau (1984) and extended in Mathieu's Tactics of Hope (2005), tactics and strategies theorize the impact of integrating with powerful institutions or remaining independent. Using narrative illustrations from their own graduatefounded engagement program, the authors argue that the dichotomous framework of tactics and strategies does not provide the complexity necessary to successfully maneuver within institutional and community dynamics. Instead, tactics and strategies is reconceptualized as the basis of a decision-facilitating heuristic for graduate-student led community initiatives to increase students'agency to navigate institutional forces.
\end{abstract}

Over the past decade, attention has been turning to graduate education as the "next frontier of the service-learning and civic engagement movements" (O'Meara 2007, p. 2). Community engagement can allow graduate students to connect their work to social issues; approach subjects in more complex ways and with broader epistemologies; reflect on career choices and disciplinary values; and gain skills in research, teaching, communication, administration, and collaboration (Druschke, Bolinder, Pittendrigh, \& Rai, 2015; Garrison \& Jaeger, 2014; Laursen, Thiry, \& Litson, 2012; O’Meara \& Jaeger, 2006; Sandmann, Saltmarsh, \& O'Meara, 2008; Schnitzer \& Stephenson, 2012). Graduate students are frequently looking for "meaningful work" (Austin, 2002), and community engagement may be one path toward finding that meaning while also developing practical and academic skills. Morin, Jaeger, and O'Meara's (2016) recent overview of engaged graduate education revealed a growing landscape that now features increased opportunities for interdisciplinary scholarship, a network of organizations that provide professional development to engaged graduate students, and a steady growth in the number of community-based dissertations. Engaged faculty are integrating service-learning in graduate coursework (Kajner, Chovanec, Underwood, \& Mian, 2013; Rentz \& Mattingly, 2005; Ross, 2010) and including graduate students in ac- tion research and community organizing initiatives they facilitate (Kuebrich, 2015).

Graduate students are also starting their own community-based projects, which invites a host of different challenges and opportunities than those projects directed by faculty members. Studentinitiated and -directed projects range from writing groups for hospice patients conceived by a creative writing MFA student (Bunn, 2012), to a program joining high school and college classes for linked curriculum and field trips that has been coordinated by $\mathrm{Ph} . \mathrm{D}$. students for twelve years (Shah, in press), to a campus food pantry launched by a sociology graduate student (Habenicht, 2015). As Parks noted in an interview (Harvey, Kirklighter, \& Pauszek, 2015), coordinating a community program as a graduate student involves distinct challenges, as graduate students often do not have high-level access to the institutional network of the university to troubleshoot issues; they may not have connections to university administrators or community collaborators who have clout to garner support for intended projects; and they operate under the ticking clock of graduate funding, which poses challenges for the slow work of establishing and nurturing sustained relationships. Furthermore, graduate students may not be adequately equipped by their programs and departments to navigate the complex institutional dynamics involved in directing civic engagement 
projects. As O'Meara (2011) has identified, there are significant insufficiencies in the preparation of graduate students for community engagement. Coordinating a community partnership program often requires difficult decisions about mediating crossinstitutional relationships; communicating effectively with community organization and campus administrators; anticipating and addressing logistical, liability, space, and funding concerns; writing and managing grants, which must be housed in a particular institution or department; negotiating transitions in anticipation of graduation; and balancing one's own labor conditions, as initiating a community partnership is often unpaid and challenging to translate into work valued by institutions beyond a "service" CV line. All of this must be accomplished within the changing landscape of higher education, which includes a pervasive neoliberal focus on revenue production that can eclipse civic engagement (Shaffer, 2012) and the swirling anxiety about publishing for job market competitiveness given the dwindling number of tenure-track positions (Ball, Gleason, \& Peterson, 2015; Larson, Ghaffarzadegan, \& Xue, 2014).

Perhaps most difficult, graduate students must coordinate their community partnerships out of liminal institutional positionalities - between faculty and student - as they often teach their own classes as instructors of record and launch their own publishable research projects, as faculty do, but they are still students. According to Turner (1969), "The attributes of liminality or of liminal personae ('threshold people') are necessarily ambiguous, since this condition and these persons elude or slip through the network of classifications that normally locate states and positions in cultural space" (p. 95). As graduate students live in the threshold between their student and faculty classifications, they occupy an ambiguous position in navigating institutional dynamics. This liminal positionality poses distinct challenges and opportunities in coordinating a community partnership, in particular as graduate students decide how or whether to integrate their engagement programs within their home department. Because of the instability in their institutional position or their limited time in graduate school, graduate students may try to stabilize the community engagement programs they initiate or direct by linking these programs officially to the university for credibility and resources. However, institutionalization is not an option for all graduate students who seek it, and joining a program to a university department can come with a significant loss of flexibility.

Mathieu (2005) has theorized this question of institutional alignment in her work on tactics and strategies, a conversation that has been taken up by numerous scholars in community writing studies. According to Mathieu, a strategic orientation comes from a place of power in which the institution "seeks to control spaces and create institutional relationships with an 'other' in the community" (p. xiv), with the goal of sustaining the same work over time. A tactical orientation is more de-centered, operating without institutional space or sponsorship and without the assumption that the work will continue long-term. In her controversial book, Mathieu argues that a tactical stance allows greater responsiveness to communities, as the focus shifts from long-term sustainability and institutional priorities to the always-moving interests of communities. Rich debate exists over whether community engagement practitioners should pursue strategic partnerships, tactical partnerships, or a hybrid model, with several scholars arguing vigorously for one model rather than the other (Mathieu; Parks, 2009), or challenging the dichotomy altogether (Feigenbaum, 2011; Holmes, 2016; Jacobi, 2016; Peeples, Rosinski, \& Strickland, 2007). Yet, discussions of tactics and strategies have yet to explicitly take into account the unique positionalities of graduate students who initiate and direct community partnerships.

This article, collaboratively written by graduate students and a faculty advisor, extends Mathieu's (2005) theory of tactics and strategies in community engagement, reconceptualizing it as a decisionmaking heuristic rather than a set of models, in order to help graduate students who initiate or direct community projects navigate the choices that can lead to a wide range of institutional configurations. We suggest that graduate students who direct community partnerships, because of their liminal institutional positionality, are caught between forces that pull them toward tactical partnerships unaffiliated with the university and long-term strategic partnerships integrated into departments. This positionality shares many similarities with other institutional roles, such as the role of adjunct faculty, that often operate on the margins of institutional power, so the heuristic we offer here may be useful to many community-engaged scholars, even as it is designed explicitly for graduate students. We use a narrative of our experience as graduate students building a community literacy organization to illustrate the particular tensions between tactics and strategies that graduate students may encounter. These tensions inform our creation of a heuristic consisting of decision-facilitating questions, which we offer as a generative tool for graduate readers initiating and directing community engagement projects. This heuristic facilitates a graduate stu- 
dent process of inquiry about their organizational vision by considering particular issues of flexibility, institutional context, and resources from their distinct liminal positionality.

\section{Tactics and Strategies: Models of Community Engagement}

The theoretical framework we apply to community projects initiated or directed by graduate students is rooted in de Certeau's (1984) notions of "tactics" and "strategies." His work, The Practice of Everyday Life, established a key distinction between these two terms. Strategies, for de Certeau, are relationships formed from a site of power to a distinct "other" outside of itself. As he explained, "[A] strategy assumes a place that can be circumscribed as proper (propre) and thus serves as the basis for generating relations with an exterior distinct from it (competitors, adversaries, 'clienteles,' 'targets,' or 'objects' of research)” (p. xix). De Certeau asserted that tactics, in contrast,

cannot count on a 'proper' (a spatial or institutional localization), nor thus on a borderline distinguishing the other as a visible totality ... Because it does not have a place, a tactic depends on time - it is always on the watch for opportunities that must be seized 'on the wing.' (p. xix)

As de Certeau describes, tactics are "the art of the weak" (p. 37). In other words, de Certeau's strategies rely on the power of an institution controlling spaces, while tactics rely on the creative and responsive daily practices of those who do not have the same control over their spaces.

De Certeau's strategies and tactics have become an important theoretical framework in community literacy studies within English Composition, beginning with Mathieu's (2005) application of de Certeau's ideas to community projects as either "strategically oriented" or "tactically oriented" in her influential text Tactics of Hope: The Public Turn in English Composition. Mathieu framed strategic orientations as those that control space through official alignment with universities and, through their institutional power, form relationships with a distinct "other" in the community ${ }^{1}$. For Mathieu, community projects that operate from the positionality of institutions, such as a partnership coordinated by a service-learning center or sponsored by a department, would be best described as having a strategic orientation (p. xiv). Mathieu makes a compelling and controversial call for "tactical" partnerships, which she envisions as grounded in personal relationships rather than institutional priorities, al- lowing individual relationships to lead to small, short-term projects that fit a particular goal at a particular time. Her tactical partnerships are similar in some ways to what is known in the wider servicelearning literature as "transactional" relationships: temporary, project-based collaborations (Clayton, Bringle, Senor, Huq, \& Morrison, 2010; Enos \& Morton, 2003) - though the scholars who originally proposed the term, Morton and Enos (2003), frame transactional partnerships as insufficient, arguing that faculty should strive toward long-term, "transformational" partnerships. Mathieu moves in the other direction, actively pursuing and valuing tactical partnerships. She illustrates her call with a series of service-learning horror stories, in which "strategic," institutionalized projects failed to be responsive to changing community interests, as the focus seemed to be keeping a project operating for the sake of claiming sustainability or fulfilling institutional priorities.

For Mathieu, pursuing a tactical partnership means forfeiting the stability that comes with a long-term, institutionalized partnership in return for more agile and responsive ways of collaborating with the community. Mathieu offers several examples of tactical work in action, including a collaboration with the Chicago street paper Streetwise, a paper written and sold by people experiencing homelessness. Mathieu had developed strong relationships with several of the homeless writers, and when they feared that their words were being read only because of charitable attitudes, Mathieu collaborated with them and a local theater director to develop a short-term theatrical bus tour of Chicago, "Not Your Mama's Bus Tour," written and performed by an ad-hoc cast of actors experiencing or who had experienced homelessness. While the tour ended after just a few weeks because the local police threatened to tow the bus away for not obtaining the required permits, the tour was still a meaningful act of creation and communication for the writers/performers and the audience.

Mathieu's example is tactical not only in that the partnership did not have control of its own space or enjoy institutional university privileges, but also in how it was able to be quickly responsive to the community members without substantial concern for the values, goals, and accountability systems of the university as an institution. While Mathieu saw potential drawbacks for community-based work built on tactical orientations, she ultimately argued that tactics are more ethical alternatives to strategies in community collaborations because of the flexibility they offer. She would later nuance this argument (2013), suggesting that partnerships should always begin tactically, while some contexts 
may call for projects to evolve toward a more strategic orientation, but Mathieu remains one of the most compelling voices championing a tactical approach.

Mathieu's influential argument has been answered by others, who raise thoughtful questions about both her dichotomy of tactics and strategies and her privileging of tactical partnerships. For example, Parks (2009) argued that strategic partnerships are often ultimately more ethical, as they require institutional accountability. Parks offered the example of a collection of community stories published by his English department, which residents felt misrepresented their community. Because the publishing project was strategically sponsored by the department and the story collection was integrated into the curriculum, the university was obligated to work to fix the issue - it affected not just the community but the university as well. Parks wrote,

For this reason, I argue that the 'hope' of such community-based work can be realized only by the creation of strategic university spaces that bring with them a collective ethical and institutional commitment to the numerous literacy populations that make up a neighborhood, city, or state. (p. 517)

While Parks advocates for a more strategic model, other scholars have suggested various hybrid approaches (Clifton, 2013; Feigenbaum, 2011; Holmes, 2016; Jacobi, 2016; Peeples, Rosinski, \& Strickland, 2007; Rousculp, 2014). Holmes, for example, calls for strategic structures within institutions that also allow room for what she terms "morphing" - adaptations that allow greater responsiveness to shifting contexts. Feigenbaum (2011) resisted the dichotomy between tactics and strategies altogether, arguing for tactics that "ultimately have strategic consequences" (p. 49 ), and suggesting that engaged scholars work to change institutions to make them more ethical and relationship-centered, rather than attempting to insulate community engagement efforts from institutional priorities. An edited collection devoted to the debate about tactics and strategies, Unsustainable: Re-Imagining Community Literacy, Public Writing, Service-Learning, and the University (Cella, \& Restaino, 2013), included a range of scholars from various institutional positionalities weighing in on the question. Scholars have discussed how dynamics specific to various positionalities can impact how tactics and strategies are experienced by engaged scholars and teachers, including program administrators (Holmes, 2016; Rousculp, 2014; Sawyer, 2009), tenure-track faculty (Deans, 2013;
Donnelly, 2013), and adjunct faculty (Johnson, 2013).

However, the scholarship around tactics and strategies has yet to substantially take into account the dynamics of graduate student engagement, especially programs initiated and directed by graduate students. As we extend the discussion to include the specifics of graduate-initiated and -directed programs, we want to productively reframe the debate from a conversation about which model or hybrid version of tactics and strategies is more effective. Instead, we build on the scholarship that complicates this dichotomy to fashion a decisionfacilitating heuristic to help graduate students navigate the many choices involved in establishing an engagement project, especially deciding whether and how to connect that project to a university. To do so, we begin with a narrative illustration of how liminal graduate student status can impact the possibilities and limitations around tactical and strategic approaches to community engagement, highlighting tensions that became the foundation for our heuristic.

\section{Caught Between Tactics and Strategies: A Narrative Illustration of the Writing Lincoln Initiative}

In fall 2011, three English graduate students at the University of Nebraska-Lincoln began brainstorming ways to extend their university writing center's mission - using literacy education to work for social justice - in order to partner with members of the local community. Because the writing center only served university students and faculty members, we envisioned the Writing Lincoln Initiative (WLI) as an organization that would be flexible enough to allow collaborative relationships with a diverse range of community partners around writing projects. We imagined the WLI component of the writing center to be a project that was a hybrid of two different models: the academic writing center, utilized by our university and many other universities, which provides one-with-one writing tutoring for enrolled students; and 826 Valencia in San Francisco, a well-known community writing center which offers tutoring while also serving as a hub for various local literacy projects, including workshops, readings, publishing, and schoolpartnered programs. One of our founding members had a long-standing relationship with a community center director, and conversations between the two led to interest in a collaboration. We hoped to build our engagement around the community center's assets and goals: for example, the director envisioned us working with students in an existing innova- 
tive after-school program to improve their reading and writing skills. We also had conversations with other community partners interested in inviting employment-seeking residents to bring in their job documents and resumes for feedback.

Initially, the founders of WLI imagined an institutionalized version of our project as the default option, without awareness of the benefits, drawbacks, or complications of such an orientation. In our early conception of the project, WLI would receive support from the department and/or the university writing center to establish itself and create partnerships in the community. Our initial planning called for a mobile conception of the writing center for the first two years and a physical space in the community after that. Yet, this proposed strategic orientation was met immediately with institutional hurdles. Our university's writing center, which was fighting for its own funding at the time, was in no position to advocate for supporting a new costintensive project. Our English department faculty were encouraging but uncertain about WLI's options for funding at the university level since we were proposing a new graduate-student project without an established track record, direct programmatic link, or integration with faculty research agendas. Faculty also expressed concern for our positionality as graduate students with a 2:2 teaching load, graduate program requirements, and the labor demands of starting and running a community organization. As these complications emerged, we were simultaneously working to balance our responsibilities as students and teachers with the increasingly complex task of developing a new organization. Through the nature of this liminal positionality, we had limited power within the university system to bring attention to our project and little voice to ask people to consider it as the basis for a strategic partnership, echoing challenges in graduate student-initiated community projects outlined by others (Feigenbaum, 2008; Harvey, Kirklighter, \& Pauszek, 2015). Therefore, our attempts to create an institutionalized engagement project failed.

As demonstrated by this experience, our institutional positionality as graduate students shaped the initial formation of WLI as a tactical organization. We were not full members of our department; did not possess secure institutional space; and were unable to vote on department decisions. Consequently, the partnerships we formed with community members and organizations operated without university oversight or influence. We were not technically or functionally a university organization; we were a small group of Lincoln community members who happened to be university graduate students.

After our initial vision of WLI unraveled, we re- imagined what the project might be. We decided to operate outside the university's purview, taking a more flexible or tactical orientation to the project. We crystallized and strengthened our two initial partnerships - one with an after-school program at a local community center for children in grades $\mathrm{K}-5$, and one with a soup kitchen offering adult literacy classes. Thinking more tactically allowed us to adapt to our community partners' visions for our relationship rather than "delivering" the same university program at each site. The adult literacy group members wanted to develop basic literacy skills to complete their GED requirements and fill out job documents. The after-school program, on the other hand, was open to whatever type of educational programming we could offer. Keeping these unique goals in mind, in fall 2012, WLI began programming at these two locations, and our organization expanded over the next four years to include partnerships with five additional organizations and dozens of university and community participants.

As this portion of our narrative illustrates, although we felt drawn to the stability and resources that a strategic orientation would provide, initially our positionality as graduate students shaped the formation of WLI as a more tactical organization within Mathieu's framework for community engagement, and we ended up experiencing key advantages to this orientation. Most notably, we enjoyed considerable flexibility, autonomy, and agency in working with our community partners - shaping our program without departmental or institutional constraints. We chose the partners with whom we wanted to work, such as an addiction and mental health treatment center in Lincoln, without seeking university or departmental approval. We also exercised control over establishing, modifying, and dissolving our partnerships. For example, one partnership originally envisioned as a one-onone community literacy center for adults gradually evolved into a weekly writing club for adolescent men living in a group home, based on the community partner's interests. In these cases, a more tactical orientation allowed us to adapt to and re-envision these partnerships, independently and recursively, in order to address evolving contextual situations.

We also had the freedom to support and assess our work in ways we and our community partners found most useful, another tactical advantage. For example, in 2013, motivated by our goal to provide school supplies and publish a book of participants' writing, we launched an Indiegogo crowdfunding campaign online. We shared the link to help fund this campaign with faculty, family, friends, and community members alike, raising over $\$ 1200$ through the generous donations of people who knew us and our work and 
allowing us to spend the funds in whatever ways we saw fit, without the need for accounting for them in formal budgets or institutional records. We also implemented an assessment process designed in collaboration with the after-school program to measure students' progress as a result of our partnership rather than relying on university guidelines or metrics. Finally, by taking on this work independently and establishing our own credibility and structures, rather than relying on university support, we gained important knowledge, skills, and awareness that have served us throughout our graduate education, aiding our growth and development as teacher-scholars. We learned how to develop conscientious and collaborative assessment tools, identify and obtain resources outside the purview of the university, and be flexible in our curriculum development and pedagogy.

However, WLI's initial, tactical orientation also created significant drawbacks for our work, engendering a sense of being torn between desiring tactics and strategies. The money we raised through crowdfunding, for example, came from a laborintensive, one-time effort - rather than from a renewable funding stream written into a university budget. We also had serious concerns about sustaining our partnerships over time, since graduate students are an involuntarily transient population, and most of us would need to leave Lincoln to find academic jobs after graduation. Finally, we wondered about the implications of choosing to perform work that may have benefited the department in recruitment and civic engagement efforts, but was not integrated in a systematic way to support our needs.

Based on these constraints, five years after the organization's founding, we reopened a discussion about a more strategic orientation for WLI. This new trajectory of thought emerged out of our concern for sustainability: with a key member of our leadership leaving Lincoln in 2014, two others nearing the end of their respective programs, and the pool of potential graduate leaders dwindling, we worried the organization would not be sustained. Tactical relationships, such as ours, are in danger of ending naturally when those who have built the foundation of the partnerships move on; for our partnerships to survive beyond the founding members' involvement, a strategic approach rooting the organization in the institution rather than individuals seemed useful. In addition, this seemed like an opportune institutional moment to shift toward a more strategic orientation, as the English department - under the direction of a new chair - was in the midst of rebranding itself for an upcoming program review. Our colleagues were engaged in debating the purpose of the humanities, reframing their commitment to English studies, and looking for ways to make the program more "marketable" to students. When the chair circulated drafts of the department's new mission statement, we noticed how many of its articulated commitments aligned with those of WLI: "pursuing social justice," "affirming diversity," "engaging with a broad array of real and imagined communities," and "instilling a desire for civic engagement," to name just a few (University of Nebraska-Lincoln English Department, 2016). Taken together, these circumstances represented a key exigency for considering strategic opportunities alongside tactical ones, and to consider their range of possibilities more expansively.

We are now in the midst of pursuing certain strategic elements of English department affiliation, while still enacting a highly tactical approach. First, on the advice of our chair, we are considering taking the steps necessary to become a Registered Student Organization (RSO). This title comes with a few perks from the university: an organization office on campus, access to inexpensive graphic design and promotional materials, and free refreshments for our community events. These perks are especially appealing to graduate students who, occupying a liminal institutional position, must conduct the same program administration work as permanent faculty members without equivalent institutional resources. Becoming an RSO also means that the department may be able to set aside a small yearly stipend for WLI, as it has done for other graduate groups in the past. Additionally, we are creating a graduate student coordinator position for overseeing the organization's logistical and programmatic operations; with the support of our department chair, this rotating position comes with a course release, a significant benefit for overworked graduate students. Finally, we are drafting a proposal for an undergraduate service-learning course in our department curriculum, through which graduate and undergraduate students alike will be introduced to and engaged in the work of WLI in the local community.

We are now connected to the department, but peripherally so. Unlike in other department programs that involve graduate students, WLI's graduate leaders operate independently. Instead of being assigned a supervisor, we voluntarily sought a faculty advisor who provides advice and support rather than making decisions. In a move that exemplifies our complication of strategic and tactical approaches, we intentionally wrote the job description for the new graduate coordinator position to focus generally on community engagement rather than use the name WLI or specific community partners. We made this decision to build tactical flexibility into 
our new strategic structure, recognizing that particular partnerships, or even WLI as a whole, may dissolve if needed in response to changing community and university interests, even as a graduate position committed to engagement of some kind might remain. We still plan to continue other tactical moves, such as crowdfunding efforts for purchasing supplies and publishing community partners' work; continually reevaluating partnerships to decide whether they should continue or dissolve; designing programming in collaboration with community partners that may change each semester; maintaining our own budget, leadership structure, policies, and decision-making practices; and generally operating with little institutional oversight.

In reflecting on our organization's first five years, we now understand that what we lacked in founding WLI was more than just the knowledge to effectively develop a strategic partnership. We also lacked a coherent decision-making process to help us determine what we needed from a university affiliation, or whether this affiliation was ultimately the right structure for both us and our community partners at any given moment. In our role as graduate students, the absence of a decisionmaking heuristic for establishing a community organization kept us from seeing the myriad ways of constructing our partnerships in relation to our university. Since we weren't aware of Mathieu's paradigm or the other scholars who have complicated and extended it, we conceived of our organization in limited and binary terms: either institutionalized or non-institutionalized. Our distinct positions as graduate students, running a program as faculty do but without the stability of a faculty title, pulled us toward both structures simultaneously. Being torn between tactics and strategies ultimately allowed us to break from a paradigm of tactics and strategies as a dichotomy of organizational models and shaped our development of a heuristic based on Mathieu's framework and the wider conversation around it, which we outline in the next section.

\section{Moving Beyond Models: A Heuristic for Graduate Student-Initiated and -Directed Community Partnerships}

Our experiences establishing, directing, shaping, and reshaping the WLI highlight the challenges facing graduate students who often make decisions about their community engagement work without a nuanced and contextualized understanding of tactical and strategic orientations and the range of possibilities these orientations offer. Our initial efforts to define our organization can be seen as attempts to choose a model of either in- stitutionalized or noninstitutionalized community engagement, whether we had language for it at the time or not. Over time, however, our thinking expanded beyond conceptualizing tactics, strategies, and everything between as two distinct orientations or a linear trajectory from tactical beginnings to a strategic end goal. Instead, through conversations within our graduate student organization, with community partners, and with supportive faculty members, along with encountering texts that problematized a binary view of tactics and strategies (Feigenbaum, 2011; Feigenbaum et al., 2013; Holmes, 2016; Peeples et al., 2007), we began complicating and extending Mathieu's framework in light of our own experience. Together, we generated a question that became central not only to our work with WLI, but also to our overall commitment to community engagement: What if we reframed tactics and strategies as a decisionmaking heuristic for graduate student use to create more ethical and effective community projects?

To this end, we have created a heuristic that reflects some of our most important areas of deliberation in order to help other graduate students think through the institutional dynamics of coordinating their own programs - which, as our experience illustrates, are often significantly different from programs coordinated by faculty. Our "Heuristic for Graduate Student-Initiated and -Directed Community Partnerships" (see Figure 1) is based on three key categories of consideration that shaped our work with WLI. The first category addresses our organizational flexibility and responsiveness in collaboration with our community partners, including questions such as, "Considering the constant turnover that comes with graduate student leadership, how important is flexibility to change partnerships, structures, values, goals, and schedules to reflect new leadership?" The second category considers our professional, institutional, and departmental context, leading us to include questions such as, "To what extent is the timing right for becoming a strategic partnership? For example, is your department currently relatively free from pressing issues like sudden budget cuts, a curriculum overhaul, or program review?" The final category explores the support and resources available to us, including the following question: "How important are institutional incentives for recruiting and sustaining other graduate students' participation?" These three themes continually resurfaced in our conversations, proposals, and meetings about our community engagement work during a time when we were alternately pulled toward both tactical and strategic orientations based on different factors of our position and situation as graduate students. 
We learned to consider these specific factors carefully, such as the inevitable turnover in our graduate leadership, the alignment between graduate student and faculty research agendas in our department, and the logistics of attempting to write our own grants as non-faculty members. Based on these considerations, we constructed the heuristic as a series of open-ended questions positioned on a spectrum between two arrows, each pointing toward either a more tactical or a more strategic orientation. Consider, for example, the first question in the heuristic: "How important to your community partners are program consistency and longevity extending beyond your graduate career?" Graduate students whose community partnerships are longstanding and revolve around consistency might be more drawn toward a strategic orientation embedded in the permanence of a university, while those less concerned with longevity might find more usefulness in a tactical, flexible, independent approach.

In our case, we carefully considered the fact that the two graduate directors of our organization, who spent several years building strong relationships with particular community partners, would eventually leave WLI behind as they moved on to faculty positions. Yet our community partners reached out to us and expressed a desire for continued, regular programming. For example, when the WLI director (author Meade) pointed out that his last year of graduate study was approaching, the community center director of programming asked to be put in touch with future leadership so that he could continue the literacy education after-school program. The center appreciated this collaboration for its ability to help them achieve assessable learning goals in an engaging way for youth participants and fulfill funding requirements from the United Way. Because longevity and consistency were clearly important to our community partners, we focused on enriching the partnerships we already had in place, recruiting new department volunteers to take over that work in our absence and seeking course releases for those volunteers, rather than starting new partnerships or endeavors during our short time in the graduate program.

Our heuristic is also oriented toward the possibilities already available to graduate students and the strengths they possess, rather than emphasizing the limitations of their complicated positionality within the institution. For example, the question "How well does your leadership style align with spontaneity and maneuverability, as opposed to consistency and longevity?" encourages graduate students to leverage the leadership abilities they already have and to view these abilities as assets for community engagement. In our case, for instance, author $\mathrm{Hu}-$ brig drew on his flexibility in meeting last-minute with leaders of a local refugee group at an IHOP at 10 P.M. Other graduate leaders, whose styles focus more on advanced preparation and organizing, pursued partnerships with more traditional and strategic planning structures.

A conceptual tool like this heuristic, which would have greatly benefitted us as we struggled to get WLI off the ground, can encourage other graduate students to think more critically, reflectively, and contingently about all the factors and dynamics involved in establishing a new organization. In choosing to present these concepts as a heuristic, we offer more possibilities within the tactics and strategies paradigm than a binary models approach, and this particular heuristic is built on the unique tension experienced by graduate students caught in the gap between the responsibility of coordinating a community engagement program and the oftenlimited resource support or institutional power available to them through universities. Graduate students experience this tension differently based on their specific liminal institutional positionality and must grapple with their own institutional context and personal assets. This heuristic allows for careful consideration and reflection on graduate students' particular circumstances throughout the process of developing and refining community partnerships.

While we have centered the perspectives and circumstances of graduate students in constructing this heuristic, we also want to acknowledge the visions, assets, and priorities of community partners as the heuristic continues to develop. Rather than recommending graduate students utilize this tool independently, we suggest using it in collaboration with community partners, and soliciting their input continuously, as the heuristic is utilized and customized for a specific partnership or context. As partnerships evolve, the use of this tool and the answers to the questions can change accordingly. Future iterations of the heuristic might also include sections designed by community partners so as to reflect the shared interests and goals of both community and campus partners.

\section{Conclusion}

Based on our particular experience with WLI, the themes of flexibility and responsiveness; professional, institutional, and departmental context; and support and resources emerged as central inquiry points to feature in our heuristic for graduate student-initiated and graduate-directed community partnerships. Yet this heuristic is a draft based on our specific experience, and we invite other gradu- 
Figure 1

Heuristic for Graduate Student-Initiated and-Directed Community Partnerships

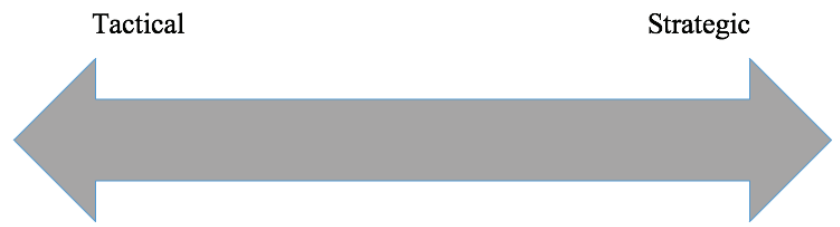

Flexibility and Responsiveness

Less How important to your community partners are program consistency and longevity extending beyond your Mor graduate career?

Less How important to your community partners is the credibility that may come with university affiliation?
More $\quad$ To what extent might university affiliation be a hindrance to credibility with your community partners (e.g., because of past conflicts with the university)?

More How important is your ability to quickly and easily change the parameters of the partnership (activities, goals, timeframe, participants, etc.)?

More How important to you or your community partners is control over designing, implementing, and dissolving partnerships as needed?

More How well does your leadership style align with spontaneity and maneuverability, as opposed to consistency and predictability?

More Considering the frequent turnover that comes with graduate student leadership, how important is flexibility to change partnerships, structures, values, goals, and schedules to reflect new leadership?

More How important is the freedom to craft assessment tools focused only on interests of your organization and community partners (rather than prioritizing the interests of the university)?

Less

Less

Less

Less

Less

Professional, Institutional, and Departmental Context

Less To what extent do your department's mission, values, and trajectory connect to community engagement?

Less To what extent is your department aware of and benefitting from your project (e.g., using it to recruit faculty and graduate students)?

Less How well does community engagement align with the research interests of faculty in your department?

Less How connected are you to faculty members who have the time, skills, and investment to support your project

More and champion it at the institutional level?

Less How capable and interested are you in navigating institutional university dynamics at the administrative level?

Less To what extent is the timing right for becoming a strategic partnership? For example, is your department cur-

Less rently relatively free from pressing issues like sudden budget cuts, a curriculum overhaul, a program review?

More To what extent does your research depend on a sustained, stable research site in the community?

More How susceptible is your partnership to more restrictive university liability policies if the partnership were to become an official university program (e.g., policies around working with minors; transportation off-site; Less dealing with trauma, criminality, drug abuse, etc.)?

Support and Resources

Less How necessary is significant outside funding for your project?

Less In order for you to feel personally capable of doing this work, how important is sponsorship in the form of a stipend, teaching release time, or other compensation from the university?

Less If the project will remain after your graduation, to ethically and effectively recruit new leadership, how critical is sponsorship in the form of a stipend, teaching release, or other compensation from the university?

Less How important are institutional incentives for recruiting and sustaining other graduate students' participation?

Less How important are material resources (an office, meeting room, website, transportation, food, printing, office supplies, etc.) to your partnership?

Less To what extent do you feel that you need existing institutional systems and knowledge (access to communication channels, connections to potential volunteers, templates for documents and texts, record-keeping systems, etc.) from university sponsors?

Less Given that most grants require 501c3 status (either through a nonprofit or the university), how necessary is it for you to align with a university department to access grant funding?

Less How likely is it that your department has the capacity to offer financial resources to the project? sight (ability to crowdfund, reimbursement stipulations, etc.)? 
ate students involved in leading community engagement projects - and faculty working with graduate students, as well as community partners - to view this tool as open to revisions and additions, and to prioritize these questions as they see fit. We also invite contributions from practitioners in a range of community and institutional positionalities who might experience a similar gap between responsibility and resources, such as adjunct faculty. Our aim in producing this first draft of the heuristic is to offer a tool for future graduate students, such as the incoming WLI members in our program, to consider how best to initiate community engagement efforts from their own positionalities. Rather than advising others to follow a tactical or strategic path, or to consider the various hybrid or morphed models suggested by other scholars who have extended and complicated Mathieu's framework, we offer this heuristic as a catalyst for an ongoing, recursive process of inquiry. Just as our own work frequently swings between tactical and strategic visions, opening up ruptures and opportunities between them, we hope other graduate students who are establishing and leading community engagement projects will make decisions about what those projects look like and how they evolve based on their own highly contextualized institutional and community positionalities. Equipped with this conceptual tool, graduate students can view their liminal positionality not as a deficiency but as a space of agency, creativity, and possibility.

\section{Note}

${ }^{1}$ While Mathieu and most scholars that pick up the conversation after her, including the authors of this article, apply strategies specifically to the university as an institution, future scholarship might also consider how community organizations, or even governments, can also function as institutions. As Feigenbaum (2014) argues, we can never step fully outside the power structures of institutions.

\section{References}

Austin, A. E. (2002). Preparing the next generation of faculty: Graduate school as socialization to the academic career. The Journal of Higher Education, 73(1), 94-122.

Ball, D. M., Gleason, W., \& Peterson, N. J. (2015). From all sides: Rethinking professionalization in a changing job market. Pedagogy, 15(1), 103-118.

Bunn, A. (2012). Firsts and lasts: Lessons from launching the Patient Voice Project at the Iowa Writers' Workshop. In A. Gilvin, G. M. Roberts, \& C. Martin (Eds.), Collaborative futures: Critical reflections on a publicly active graduate education (pp. 301-311). Syracuse, NY: The Graduate School Press.
Cella, L., \& Restaino, J. (Eds.). (2013). Unsustainable: Re-imagining community literacy, public writing, service-learning, and the university. Lanham, MD: Lexington Books.

Clayton, P. H., Bringle, R. G., Senor, B., Huq, J., \& Morrison, M. (2010). Differentiating and assessing relationships in service-learning and civic engagement: Exploitative, transactional, or transformational. Michigan Journal of Community Service Learning, 16(2), 5-21.

Clifton, J. (2013). Mastery, failure, and community outreach as a stochastic art: Lessons learned with the $\mathrm{Su}$ danese diaspora in Phoenix. In J. Restaino \& L. Cella (Eds.), Unsustainable: Re-imagining community literacy, public writing, service-learning, and the university (pp. 227-262). Lanham, MD: Lexington Books.

de Certeau, M. (1988). The practice of everyday life. Berkeley: University of California Press.

Deans, T. (2013). Sustainability deferred: The conflicting logics of career advancement and community engagement. In J. Restaino \& L. Cella (Eds.), Unsustainable: Re-imagining community literacy, public writing, service-learning, and the university (pp. 101112). Lanham, MD: Lexington Books.

Druschke, C. G., Bolinder, M. M., Pittendrigh, N., \& Rai, C. (2015). Designing the future: The long term impact of service learning on graduate instructors. $R e$ flections: Public Rhetoric, Civic Writing, and Service Learning, 14(2), 22-50.

Donnelly, M. (2013). Hope and despair, risk and struggle: (j)WPA work, service-learning, and the case for baby steps. In J. Restaino \& L. Cella (Eds.), Unsustainable: Re-imagining community literacy, public writing, service-learning, and the university (pp. 113134). Lanham, MD: Lexington Books.

Enos, S., \& Morton, K. (2003). Developing a theory and practice of campus-community partnerships. In B. Jacoby (Ed.), Building partnerships for servicelearning (pp. 20-41). San Francisco: Jossey Bass.

Feigenbaum, P. (2008). The push and pull of being publicly active in graduate school. Reflections: Public Rhetoric, Civic Writing, and Service Learning, 7(3), n. p. Retrieved from https://reflectionsjournal.net

Feigenbaum, P. (2011). Tactics and strategies of relationship-based practice: Reassessing the institutionalization of community literacy. Community Literacy Journal, 5(2), 47-66.

Feigenbaum, P. (2014). Collaborative imagination: Earning activism through literacy education. Carbondale, IL: Southern Illinois University Press.

Feigenbaum, P., Douglas, S., \& Lovett, M. (2014). Tales from the crawl space: Asserting youth agency within an unsustainable education system. In J. Restaino \& L. Cella (Eds.), Unsustainable: Re-imagining community literacy, public writing, service-learning, and the university (pp. 33-53). Lanham, MD: Lexington Books.

Garrison, J. D., \& Jaeger, A. J. (2014). From serendipity to resolve: Graduate student motivations to teach using service-learning. Michigan Journal of Community Service Learning, 20(2), 41-53. 
Habenicht, L. (2015, August 7). The pop up pantry: How one student convinced her university to combat student hunger. Street Sense. Retrieved from http://www. streetsense.org/article/the-pop-up-pantry-how-onestudent-convinced-her-university-to-combat-studenthunger/

Harvey, W., Kirklighter, C., \& Pauszek, J. (2015). Interview with Steve Parks. Reflections: Public Rhetoric, Civic Writing, and Service Learning, 14(2), 7-12.

Holmes, A. (2016). Public pedagogy in composition studies. Urbana, IL: NCTE.

Jacobi, T. (2016). Against infrastructure: Curating community literacy in a jail writing program. Community Literacy Journal, 11(1), 64-75.

Johnson, K. (2013). Mobile sustainability: An adjunct's development of a permanent practice. In J. Restaino \& L. Cella (Eds.), Unsustainable: Re-imagining community literacy, public writing, service-learning, and the university (pp. 135-160). Lanham, MD: Lexington Books.

Kajner, T., Chovanec, D., Underwood, M., \& Mian, A. (2013). Critical community service learning: Combining critical classroom pedagogy with activist community placements. Michigan Journal of Community Service Learning, 19(2), 36-49.

Kuebrich, B. (2015). White guys who send my uncle to prison: Going public within asymmetrical power. College Composition and Communication, 66(4), 566590.

Larson, R. C., Ghaffarzadegan, N., \& Xue, Y. (2014). Too many $\mathrm{PhD}$ graduates or too few academic job openings: The basic reproductive number R0 in academia. Systems Research and Behavioral Science, 31(6), 745750 .

Laursen, S. L., Thiry, H., \& Liston, C. S. (2012). The impact of a university-based school Science outreach program on graduate student participants' career paths and professional socialization. Journal of Higher Education Outreach and Engagement, 16(2), 47-78.

Mathieu, P. (2005). Tactics of hope: The public turn in composition. Portsmouth, NH: Boynton Cook Publishers.

Mathieu, P. (2013). After tactics, what comes next? In Unsustainable: Re-imagining community literacy, public writing, service-learning, and the university (pp. 17-31). Lanham, MD: Lexington Books.

Morin, S. M., Jaeger, A. J. \& O’Meara, K. (2016). The state of community engagement in graduate education: Reflecting on 10 years of progress. Journal of Higher Education Outreach and Engagement, 20(1), 151-156.

O'Meara, K. (2007). Graduate education and civic engagement. NERCHE Brief no. 20. Boston: New England Resource Center for Higher Education.

O’Meara, K. (2011). Faculty civic engagement: New training, assumptions, and markets needed for the engaged American scholar. In J. Saltmarsh \& M. Hartley (Eds.), To serve a larger purpose: Engagement for democracy and the transformation of higher education (pp. 177-190). Philadelphia: Temple University Press.

O’Meara, K., \& Jaeger, A. J. (2006). Preparing future faculty for community engagement: Barriers, facilitators, models, and recommendations. Journal of Higher Education Outreach and Engagement, 11(4), 3-26.

Parks, S. (2009). Strategic speculations on the question of value: The role of community publishing in English Studies. College English, 71(5), 506-527.

Peeples, T., Rosinski, P., \& Strickland, M. (2007). "Chronos" and" Kairos", strategies and tactics: The case of constructing Elon University's professional writing and rhetoric concentration. Composition Studies, 35(1), 57-76.

Rentz, K., \& Mattingly, A. (2005). Selling peace in a time of war: The rhetorical and ethical challenges of a graduate-level service-learning course. Reflections: A Journal of Public Rhetoric, Civic Writing, and Service Learning, 4(2), 103-122.

Ross, L. (2010). Notes from the field: Learning cultural humility through critical incidents and central challenges in community-based participatory research. Journal of Community Practice, 18(2-3), 315-335.

Rousculp, T. (2014). Rhetoric of respect: Recognizing change at a community writing center. Urbana, IL: NCTE.

Sandmann, L. R., Saltmarsh, J. \& O’Meara, K. (2008). An integrated model for advancing the scholarship of engagement: Creating academic homes for the engaged scholar. Journal of Higher Education Outreach and Engagement, 12(1), 47-64.

Sawyer, P. (2009). The writing program and the call to service: A progress report from a land grant university. Michigan Journal of Community Service Learning, 15(2), 68-76.

Schnitzer, M. \& Stephenson, M. (2012). Reimagining the links between graduate education and community engagement. In A. Gilvin, G. M. Roberts, \& C. Martin (Eds.), Collaborative futures: Critical reflections on a publicly active graduate education (pp. 269-284). Syracuse, NY: The Graduate School Press.

Shaffer, T. T. (2012). The land-grant system and graduate education: Reclaiming a narrative of engagement. In A. Gilvin, G. M. Roberts, \& C. Martin (Eds.), Collaborative futures: Critical reflections on a publicly active graduate education (pp. 49-74). Syracuse, NY: The Graduate School Press.

Shah, R. W. (in press). The courage of community members: Community perspectives of engaged pedagogies. College Composition and Communication.

Turner, V. (1969). The ritual process: Structure and antistructure. London: Routledge.

University of Nebraska-Lincoln English Department. (2016). The department of English: An education in imaginative reasoning. Lincoln, Nebraska: Mission Statement Committee.

\section{Authors}

ADAM HUBRIG (adamhubrig88@gmail.com) is a PhD student in composition and rhetoric at the University of Nebraska-Lincoln, where he serves as codirector of the Writing Lincoln Initiative, co-director 
of the Nebraska Writing Project, a Husker Writers teaching partner with a local high school teacher, and associate coordinator of composition. His research focuses on community literacy and civic engagement. $\mathrm{He}$ is currently researching the connection between argument writing and civic engagement and enjoying a rich partnership between the Nebraska Writing Project and the U. S. National Parks.

KATIE McWAIN (mcwaink@gmail.com) is a $\mathrm{PhD}$ candidate in composition and rhetoric at the University of Nebraska-Lincoln, where she serves as co-director of the Writing Lincoln Initiative and a Husker Writers teaching partner with a local high school teacher. In addition to community literacy, her research interests include teacher development, program administration, and high school-college partnerships. She is currently conducting a multisite study of teacher development across institutional contexts in the Midwest.
MARCUS MEADE (meademarcus@gmail.com) is an assistant professor, General Faculty, in the Academic and Professional Writing Program at the University of Virginia and former co-director and founding member of the Writing Lincoln Initiative. His research interests include writing-related transfer, composition pedagogy, critical pedagogy, and program administration. He is currently researching the rhetoric of sports violence in America.

RACHAEL W. SHAH (Wendler.Shah@unl.edu) is an assistant professor of English at the University of Nebraska-Lincoln, where she is the faculty advisor of Writing Lincoln Initiative. She is also the former graduate-student coordinator of the Wildcat Writers engagement program. She teaches undergraduate and graduate courses on public rhetoric, community literacy, and writing pedagogy, and she is working on a book that explores community perspectives on university-community partnerships. 